\title{
Mangroves Restoration and Observation in Kaohsiung Jhong-Dou Wetland*
}

\author{
Lai Jung-Yi \\ Chung Yuan Christian University, Taoyuan, Taiwan \\ Laboratory for Environment and Form, Taipei, Taiwan
}

The ecosystems of Kaohsiung are rich and diverse. Examples of ecosystems include the tropical rainforest ecology, marine ecology of the coastal forests, and the estuary type ecology of mangrove forests. The Jhong-Dou Wetland Park is situated in the Jhong-Dou Redevelopment Zone, 2.5km from the Lover River Estuary. This area is defined by brackish aquatic environments - a mixture of fresh and salt water, and fulfills the criteria for mangrove restoration. It is expected that the current restoration project will recreate an epitome of the once-diverse, co-existing mangrove species of Kaohsiung's past, and improves upon the functions of environmental education. The initial mangrove species planned for restoration are the existing Kandelia obovata, Rhizophora stylosa, Avicennia marina and the Lumnitzera racemosa populations of the Kaohsiung area. These plants will be placed in experimental habitats that correspond to the unique micro-climates required for the growth of each species, and the mangrove-associated plants will also be restored concurrently in the terrestrial environments behind the mangrove forests. The process of restoration will be monitored by academia, as well as providing reference for subsequent mangrove environment restoration efforts. The main purpose of this research in these four mangrove species of this wetland park is to understand their adaptation to the rehabilitating environment, and be able to feedback these information to the design and maintenance team of the park. The research method is to observe and record their growing status, also execute a survey on the nearby mangrove habitation. The observation has started on December 1st of 2010, and still has been continued carry on since then. From the research result, it shows that the Avicennia marina (Forsk.) Vierh. and Lumnitzera racemosa Willd. are the two species that had been well adapted to this wetland park. It was recommended to the Kaohsiung City Government that the restoration of the extinct Ceriops tagal and Bruguiera gymnorrhiza can be achieved through foreign species exchanges (the species must be identified before introduction), and that plans for monitoring the flora and fauna in the park should be drafted to record the ecological alterations of the Jhong-Dou Wetlands. This will pronounce the ecological importance of Kaohsiung on a global, geographical scale. Lastly, the Government should draw up plans of mangrove forest maintenance in order to sustain the ecological and landscape recreational functions of the Jhong-Dou Wetland Park.

Keywords: mangroves, ecological restoration, vegetation monitoring, maintenance

\footnotetext{
*Acknowledgement: This paper was presented at Asian Wetland Symposium (AWS) in Sabah, Malaysia, in July 2011. This paper would like to thank the Kaohsiung City government's Public Works Bureau and Urban Development Bureau for the contribution of project information on wetland development in Kaohsiung, and the National Taiwan University's Herbarium for species identification and mangrove species information.

Lai Jung-Yi, Ph.D. candidate, Chung Yuan Christian University, Laboratory for Environment and Form.

Correspondence concerning this article should be addressed to Lai Jung-Yi, 1F., No.7, Aly. 1, Ln. 109, Sec. 2, Baofu Rd., Yonghe Dist., New Taipei City 234, Taiwan. E-mail: lai.roy@msa.hinet.net.
} 


\section{Introduction}

Situated on the southwestern coast of Taiwan, the city of Kaohsiung boasts a coast line that stretches some 20 kilometers, and has multiple rivers like the Love River, Houjing River and the Qianzhen River feeding into the coastal bay. Ponds and ditches from the agricultural society of the past interweave with the crossroads of the present between rice paddies, reflecting the city's diverse hydrological culture. However, the development of industrialized commerce resulted in river pollution, disappearance of wetlands, and filled-up ponds, changes that have brought ecological disasters upon the city. In recent years, with rising environmental awareness and the public's desire to undo the damages, the Kaohsiung City government has pushed forward public policies designed to restore and reconstruct rivers and wetlands, revitalize the landscapes, and bring happiness back to the people of Kaohsiung (excerpted from the Public Works Bureau of Kaohsiung City government's Discovering Beautiful New Kaohsiung).

Since the year 2000, with the intention to provide ecological education and flood prevention, the Kaohsiung City government has been converting many existing aquatic environments in the city into wetland parks with the aid of ecological engineering. Once completed, the City government plans to connect these wetlands into an interlinked "Urban Wetland Eco-Corridor", which will span the length of the city from north to south and connect the wetlands that are scattered around the city. The wetland locations that will form the basis of the corridor are: (1) Kaohsiung University Ecological Pond; (2) Yuanjhong Port Wetland; (3) Banping Lake Wetland; (4) Chouchai Wetland; (5) Neiweipi Wetland; (6) Ben-He Village Flood Detention Pond; (7) Heart of Love River's Ruyi Pond; (8) Jhong-Dou Wetland; and (9) Yanshueigang Creek Wetland. Of the wetlands, the Yuanjhong Port Wetland and the Jhong-Dou Wetland are salt-water environments, and the others are fresh-water. The planning of the wetland ecological corridor is built on the premise of bridging natural ecology and public recreation in a series of systematically designed wetland parks (see Figure 1). The corridor will provide a zone for birds, insects and plant seeds to move freely, and also allows citizens to experience co-existence with natural ecosystems. The Kaohsiung City government plans to follow through with the project and complete construction on all wetland parks in the corridor by 2010; the Love River Jhong-Dou Wetland Park will be the final construction site of the current project. The Laboratory for Environment and Form (LEF) was commissioned in 2009 to initiate the research phase of the current project.

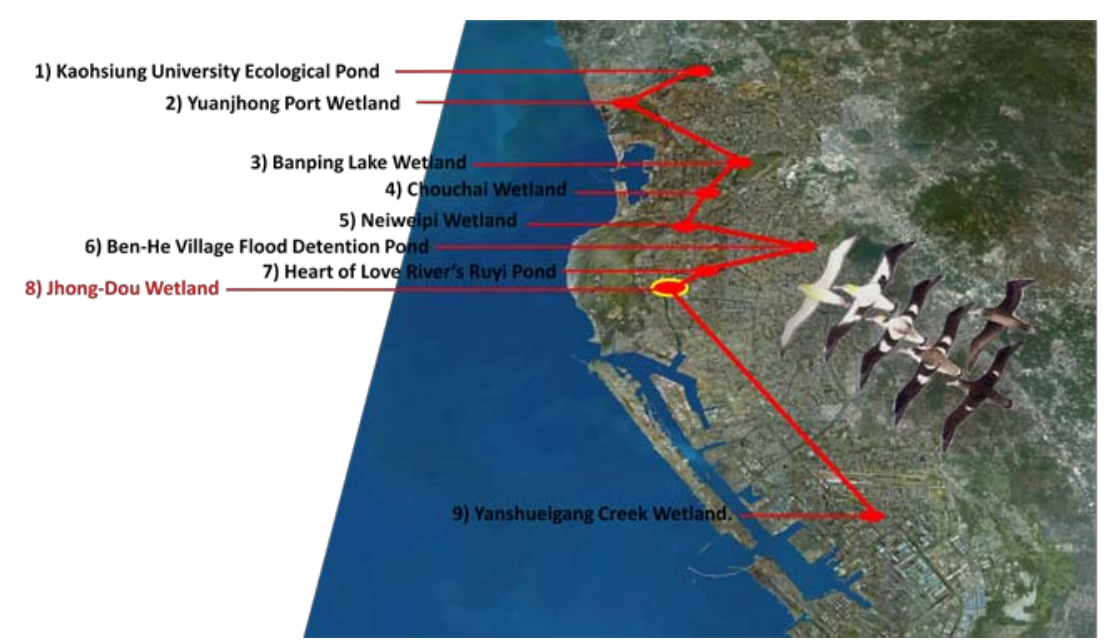

Figure 1. Graphical representation of the wetland eco-corridor connections in Kaohsiung City. Source: Compiled by the current study. 


\section{Site Description}

The coordinates of Kaohsiung City are: longitude $120^{\circ} 14 ' 30^{\prime \prime}$ to $120^{\circ} 23 ' 30^{\prime \prime}$, latitude $22^{\circ} 30^{\prime} 30^{\prime \prime}$ to $22^{\circ} 45^{\prime} 30^{\prime \prime}$. The west of the city faces the Strait of Taiwan, and the Bashi Channel. Port of Kaohsiung is an important trans-shipment center for the Indian Ocean and the North Eastern Asia, and one of the few international harbors in Taiwan. The terrain of Kaohsiung is generally flat, aside from a few free-standing coral-reef formations like the Banping Mountain and the Shou-shan Mountain. The modern day Port of Kaohsiung was constructed out of the natural lagoon that once existed. The city is situated south of the Tropic of Cancer, in a region of warm year-round climate and tropical monsoons. The monthly average temperature in 2010 was $25.2^{\circ} \mathrm{C}$, lowest in January at $17.5^{\circ} \mathrm{C}$, and highest in July at $29.5^{\circ} \mathrm{C}$; the monthly average relative humidity was $74.5 \%$, lowest in December at $67 \%$, and highest in September at $80 \%$. The annual sunshine duration was 2,309 hours, lowest in January at 130.2 hours and highest in May at 238.6 hours. The average rain duration $(\geq 0.1 \mathrm{~mm})$ was 7.1 days, lowest in March and December at one day and highest in August with 17 days. The annual precipitation was 2,167 mm, lowest in March at an average of $1 \mathrm{~mm}$, and highest in July at an average of $437 \mathrm{~mm}$.

During the Japanese Occupation (1895-1945), the Japanese began developing Kaohsiung into a small scale port city, and by 1908 large-scale modernization of Port of Kaohsiung was underway. In the early 1940s, the Japanese began developing industries in Kaohsiung; however, by the end of World War II, most of Port of Kaohsiung had sustained heavy damage. When the Nationalist Government came to Taiwan after the war, normal operation was gradually restored in Port of Kaohsiung, and an export processing zone was established in Nanzi. During the 1970s, large ship-building plants, steel foundries and petroleum factories were established in Kaohsiung, gradually turning Kaohsiung into a center of heavy industry. At the same time, cargo volume in Port of Kaohsiung was also increasing annually, and expansion of the harbor began concurrently. However, the expansion immensely impacted the natural ecology in Kaohsiung, destroying much of the mangrove forests and coastal forests that once thrived in the area.

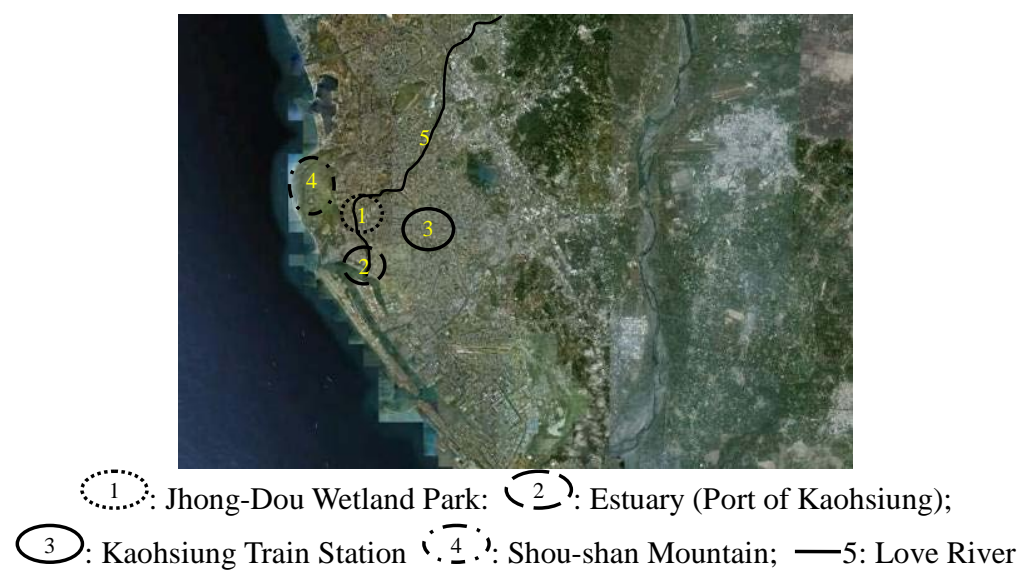

Figure 2. Position map of Jhong-Dou Wetland. Source: Google earth.

The Jhong-Dou Wetland is situated $2.5 \mathrm{~km}$ from the Love River Estuary and about $2 \mathrm{~km}$ from the Kaohsiung Train Station in downtown Kaohsiung. On the opposite bank of the construction sits the Shou-shan Mountain, a naturally up-lifted barrier reef formation. The Love River feeds into the sea water and has clear tidal displacement (see Figure 2). The 2010 Kaohsiung Marine Tidal Statistics revealed that the highest high-tide was $0.983 \mathrm{~m}$ in June, and the lowest low-tide was $-0.852 \mathrm{~m}$ in December. The total tidal displacement 
range was $1.79 \mathrm{~m}$. During the 1950s, the Jhong-Dou wetland was originally a plywood factory (Lin Shan Hao Plywood Corp and Asia Plywood Corp) (see Figure 4), the channels in the site were originally used to transport and store timbers. The Love River was originally the main transport channel for timbers, thus many channels from the factories were linked to the river for easy transportation of timbers (see Figure 5). Nowadays the factories have withdrawn from the site, but many of the channels still exist. After years of erosion from rain and lack of human interference, the channels have since turned into mudflat environments, attracting many organisms to inhabit the area. And portions of the channels were converted into civilian fish ponds (see Figure 3). The tidal displacement on the main river channel can reach $1.2 \mathrm{~m}$ and above.

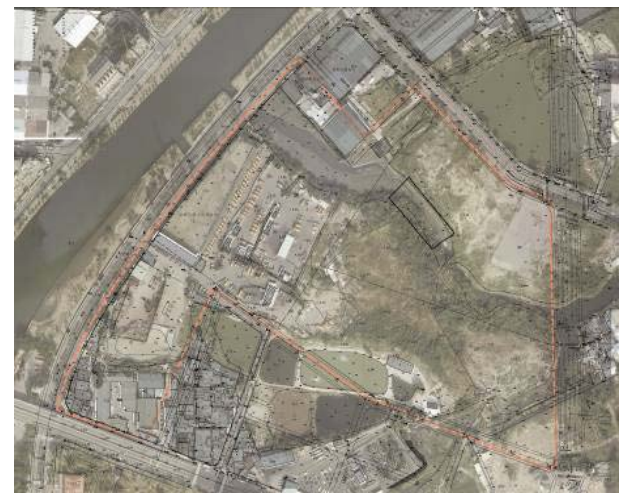

Figure 3. Love River and Jhong-Dou Wetland Park Area map. Source: Aerial Survey Office, Forestry Bureau (Aerial Survey Office, Forestry Bureau).

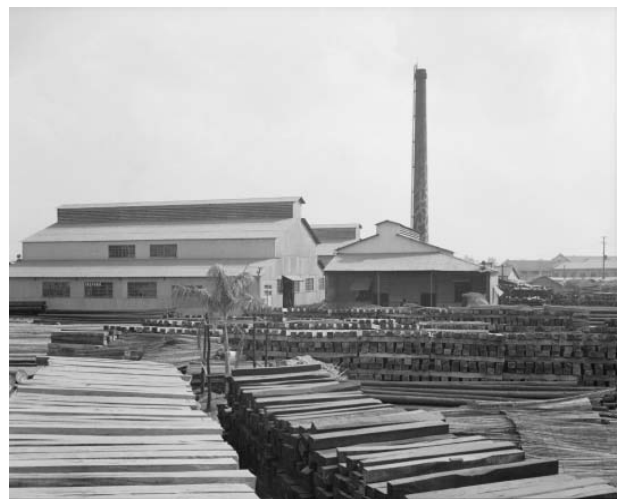

Figure 4. Exterior view of Lin Shan Hao Plywood Corp. Source: National Repository of Culture Heritage.

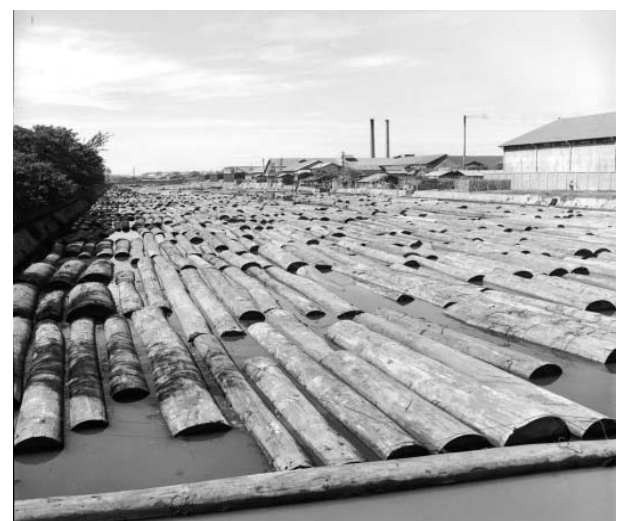

Figure 5. Lin Shan Hao Plywood Corp’s Timber Storage Pool and Factory Operation. Source: National Repository of Culture Heritage. 


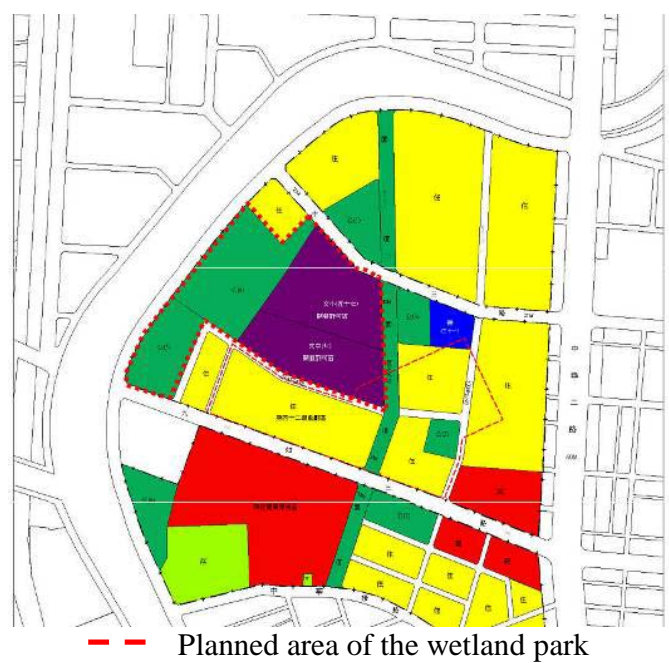

Figure 6. Kaohsiung Jhong-Dou District Urban Planning Chart. Source: Urban Development Bureau, Kaohsiung City government.

The Jhong-Dou Wetland Park is situated inside the Jhong-Dou District Industrial Zone (see Figure 6), originally containing 40 or smaller factories. Most of the lands were left undeveloped and overgrown with weeds, affecting the environmental quality and urban landscapes. The Jhong-Dou Industrial Area is close to the Kaohsiung Specific Cultural Designated Area and the Love River Sightseeing and Recreational Area. Intersected by many major roadways in the city, this area possesses ideal conditions for highly urbanized development. The City government has drafted the "Jhong-Dou District Industrial Zone Urban Re-Planning Project”, the purposes of which are to facilitate in factory removals, development of the area, and improving the urban landscapes. The project completed its detailed planning in June of 2009, and the actual construction has been progressing to this date. The basic drainage works in the re-planning zone will connect the rain water pipes from the residential areas to the Jhong-Dou Park and the school grounds, combining with the sea water from the Love River to form a mixed area of freshwater and saltwater.

\section{The Distribution and Species of Mangroves in Taiwan}

The mangrove forest is mainly comprised of plants from the family of Rhizophoraceae, and some associated plants that do not belong to the family. The mangrove biomes are groups of plants adopting biological features of mangroves, such as stilt roots, respiratory roots and viviparous seeds, and are only distributed among mangrove vegetations (Liu, 1982).

Mangrove forests are the most unique and important halophyte vegetations of the tropical and subtropical coastlines (Polunin, 1960); these plants grow on muddy coastal flats that are exposed to air during low tides. Mangroves are mainly distributed in the tropical and subtropical frost-free zones between the latitudes of $25^{\circ} \mathrm{N}$ to $25^{\circ} \mathrm{S}$; these plants are usually immersed in salt water and can be submerged completely during high tides. Due to the warm ocean currents and some cold-resistant species, the distribution of mangroves can reach as far south as the coasts of New Zealand at latitude $44^{\circ} \mathrm{S}$, and as far north as Japan's Kyushu area at latitude $31^{\circ} \mathrm{N}$ (Xue, 1995).

According to studies by Taiwanese (Liu, 1982) and international scholars (Chapman, 1970; Waisel, 1972) on the characteristics of true mangrove plants, there are approximately 55 species of mangrove plants in the world, classified into 10 families and 16 genera. The distribution of mangrove species varies between the 
Eastern and Western Hemisphere; there are more in the East at 10 families, 14 genera and 44 species, and less in the West at four families, five genera and 11 species.

Geographically, Taiwan is located in the Eastern Hemisphere, between the latitudes of $25^{\circ} \mathrm{N}$ and $25^{\circ} \mathrm{S}$, and within the natural distribution regions of the eastern mangrove forest. Previous studies by scholars (Hu, 1959; Liu, 1982) classified the mangrove plants in Taiwan to three families, six genera and six species. These plants are, respectively, Kandelia obovata (Sheue, Liu, \& Young), Rhizophora stylosa (Griff.), Bruguiera gymnorrhiza (L.) Lamk, and Ceriops tagal (Perr. C.B.Robinson) of the Rhizophoraceae family, Avicennia marina (Forsk.) Vierh of the Verbenaceae family, and Lumnitzera racemosa (Willd) of the Combretaceae family. Once the center of mangrove distributions in Taiwan, Port of Kaohsiung contained all mangrove plants with the exception of Kandelia obovata. With the recent expansion of the harbor and pollutions from industrial waste, the mangrove forests in Port of Kaohsiung have all but disappeared (Liu, 1982), and resulted in the extinction of the Ceriops tagal and Bruguiera gymnorrhiza species in Taiwan. There are now only four mangrove species left in Taiwan, and their distributions are: Kandelia obovata in the Taipei and Taoyuan areas; Kandelia obovata and Avicennia marina in the Hsinchu and Miaoli areas; Kandelia obovata and Avicennia marina in the Taichung and Changhua areas; Kandelia obovata, Avicennia marina and Rhizophora stylosa in the Chiayi areas; Kandelia obovata, Avicennia marina, Rhizophora stylosa and Lumnitzera racemosa in the Tainan, Kaohsiung and Pingtung areas. With all four species present, the highest distributions of mangroves in Taiwan are found in the Tainan and Kaohsiung/Pingtung areas. Due to the rocky reef terrains, no records of mangrove distribution are found on the Eastern Coast of Taiwan.

\section{Planning Concepts of the Jhong-Dou Wetland Park}

The planning of the Jhong-Dou Wetland Park will introduce portions of the wetland topologies as defined by the Ramsar Convention on Wetlands of International Importance: (1) brackish (mangal wetlands); (2) artificial (wetlands from purified sewage); (3) salt water (lagoon wetlands); and (4) flowing water (excavated river channels) (see Figure 7). These wetlands will provide habitats for migratory water fowls. In consideration of the hierarchical vegetation topologies in the Kaohsiung Area, restoration of the Taiwanese coastal forest environments are also planned, which will include vegetation placements in the Central Island and the surrounding green spaces after the river channels have been excavated and balanced.

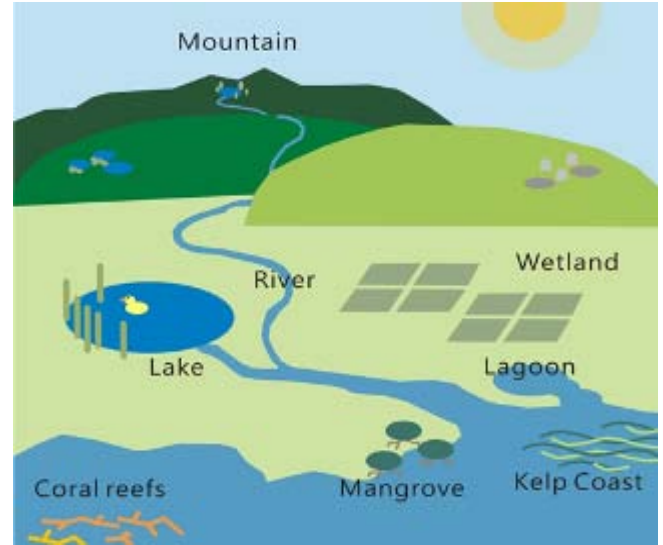

Figure 7. Wetland topologies defined by the Ramsar Convention Shoushan Mountain, Wet Plains, Ground Water, Rivers, Lakes, Artificial Wetlands, Lagoons, Mangrove Forests, Algae Farms, Coral Reefs. Source: Compiled by the current study. 


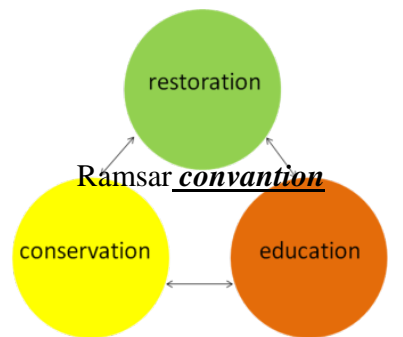

Figure 8. The spirits of RAMSAR Convention conservation, education and wise use. Source: compiled by the current study.

The Jhong-Dou Wetland Park was designed with "wise use of natural resources" in mind, which will include environmental policies on restoration, conservation and education (see Figure 8). The goals of the park will focus on restoration of the mangrove and coastal forests, conservation of bird habitats, ecological education, and recreation facilities such as bike rides, walk paths and light boat activities, fulfilling the promise of wise use of wetlands. The construction goals of the park include the following concepts:

Global definition of wetlands. According to the Ramsar Convention, water fowls make their seasonal migrations by traversing wetlands on different continents, therefore a wetland is a form of international resource. The project will examine the role Jhong-Dou Wetland will play in the international community, complimented with restoration efforts suitable for a tropical climate, and to entice global migratory birds to come and rest in Jhong-Dou when they move into Taiwan.

Building an ecological city. It is expected that the construction of the Jhong-Dou Wetland Park will fulfill six indicators of the Ecological City in the City of Kaohsiung: (1) harmonious co-existence between Nature and humans; (2) recycle and reuse of water resources; (3) green space; (4) an international communication network; (5) comfortable micro climates; and (6) active participation by citizens.

Restoration and conservation of biologically diverse coastal forests. The park will grow wetland vegetations in either salt water or fresh water environments, attracting organisms to inhabit the area, and restore the once biologically diverse coastal vegetation biomes in the history of Kaohsiung.

Zero wetland loss. Restoration of the wetlands lost during urban development by re-excavating abandoned timber storage pools and fish ponds.

The core of the wetland eco-corridor. In all of the eight completed wetland parks in Kaohsiung, the Jhong-Dou Wetland sits at the center of the eco-corridor, owing to its proximity to both the Love River and downtown areas, the historical background of the timber industry, and the unique brackish aquatic environment. These conditions make the Jhong-Dou Park stand out from all other wetlands in Kaohsiung.

Restoration site of Kaohsiung mangrove forest. The Park will be the base of mangrove restoration in Kaohsiung, utilizing its brackish aquatic conditions to restore the lost mangrove ecosystems due to urban development, harbor expansion and land reclamation.

Wetland environment monitoring and education. Establishment of a observation tower at the highest area in the park that will monitor wetland bird migrations 24 hours a day, and use environmentally-friendly canoes to conduct ecological observations, and provide records for experts to use in research and education purposes in the park.

Flood detention in the Jhong-Dou re-planning zone. Using ecological engineering to construct wetlands and river channels that will help to prevent floods from torrential rains or typhoons, protecting the citizens of 
Kaohsiung from flood damage.

Education center of Kaohsiung's eco-corridor. Set up webcams in all nine wetlands in the city and record the changes in wetland climates and environments, and collect this information back to the Jhong-Dou Wetland for all citizens and school children to observe and understand the up-to-date conditions of the eco-corridor.

\section{Mangrove Restoration in the Jhong-Dou Wetland Park}

According to archival photographs (see Figures 9-10) and studies on mangroves by scholars in Taiwan, Kaohsiung used to be one of the most crucial mangrove habitats in Taiwan. Several inland recessed harbors, including Zuoying and Port of Kaohsiung, were once coastal lagoons before port construction began, and housed the largest distribution of mangrove forests in Taiwan. With its location just $2.5 \mathrm{~km}$ from the Port of Kaohsiung estuary of the Love River, the Jhong-Dou Wetland Park's main restoration goals are to cultivate mangrove plants and potential coastal vegetation suitable for the local environment, reclaiming a piece of lost tropical wetland for the earth.

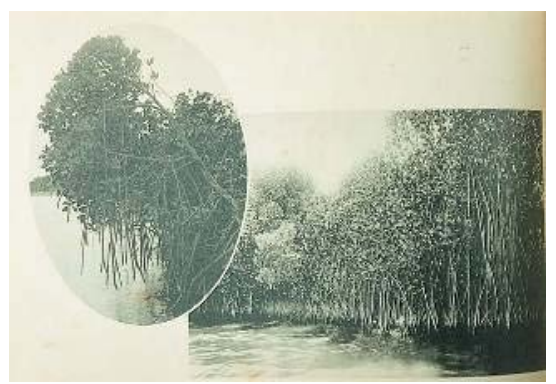

Figure 9. Avicennia marina (Forsk) Vierh in estuary wetland of Kaohsiung in early years. Source: Kaohsiung Museum of History Archival Image Digitization Project.

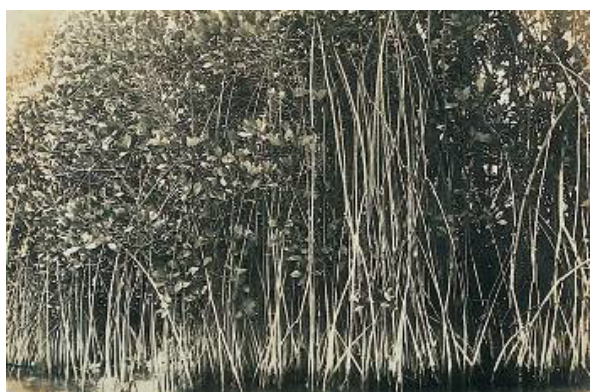

Figure 10. Lumnitzera racemosa willd in estuary wetland of Kaohsiung in early years. Source: Kaohsiung Museum of History Archival Image Digitization Project.

The estuary wetlands in Kaohsiung were once home to all six species of mangroves in Taiwan (all other areas have scattered distribution of species), however due to land reclamation and harbor construction during the Japanese Occupation and rapid urban development in the 1950s, the species of Ceriops tagal (Perr.) C.B. Robinson and Bruguiera gymnorrhiza (L.) Lamk have since become extinct in Taiwan.

The proposal recommends that in the future, the Kaohsiung City government can liaise with its sister city, Cebu of the Philippines, and introduce the extinct Ceriops tagal and Bruguiera gymnorrhiza into Taiwan for restoration through the mechanism of species exchange (verification of the species is required before importation), and devise a plan for flora and fauna monitoring in the park. In addition, the project will conduct 
vegetation cultivation in all areas according to the growth conditions of the mangroves and associated coastal plants (the mangroves in the river mud flats, and the associated plants on Central Island and the surrounding green spaces), which will recreate the natural mangrove biomes and vegetations that once existed in Old Kaohsiung. The Jhong-Dou Park will house a circular open channel that will be constructed from the dredging and connection of residual channels to abandoned timber storage pools and fish ponds. The mud flats on both sides of the open channel will be the restoration grounds of the six current and extinct Taiwanese mangrove species; it is hoped that in the future the park can become a breeding ground for parental strains of the extinct mangrove species. The aquatic zones will restore the mangroves through natural tidal cycles, and once the restoration is completed, aquatic activities such as canoeing or kayaking can be introduced to the Park, fulfilling its promises of providing recreation and restoration (see Figure 11).

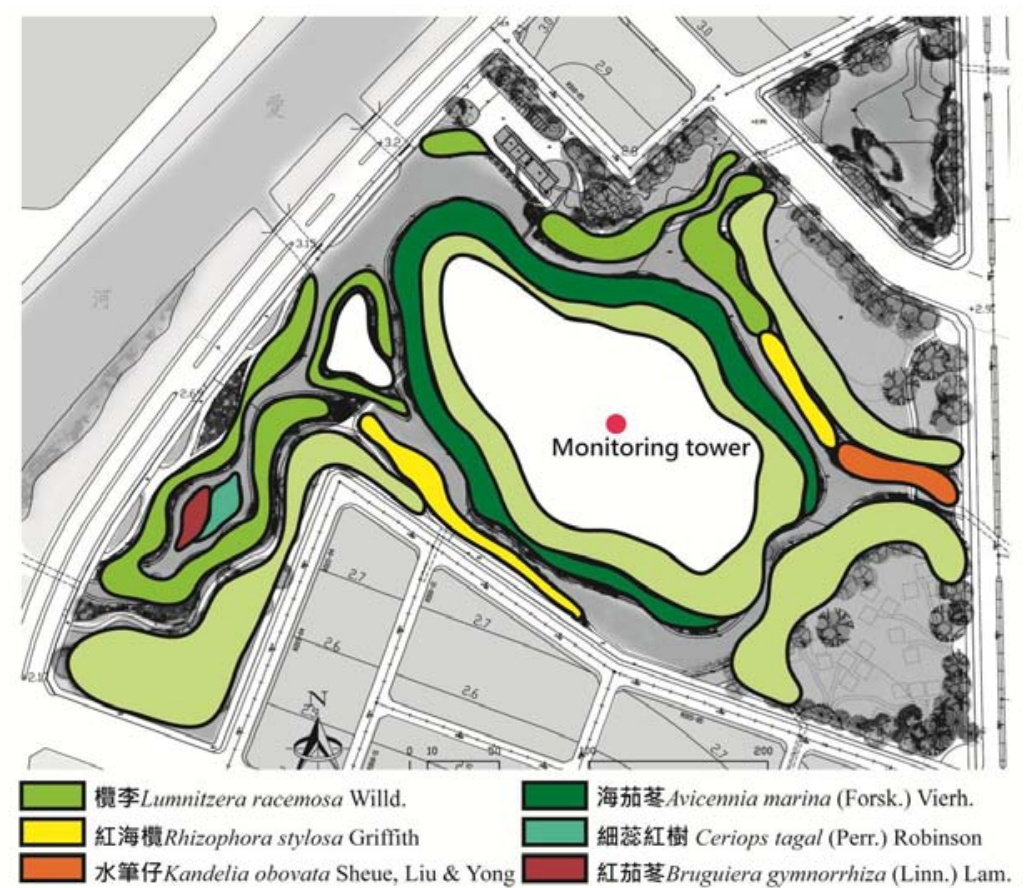

Position of webcam in the observation tower: The Central Island and the surrounding green spaces are conservation zones for coastal association plants.

Figure 11. Design floor plans. Source: Laboratory for Environment and Form.

Today's harbor cityscapes in Kaohsiung owe their roots to land reclamation efforts during the Japanese Occupation. The mangrove restoration proposal of the current project hopes that through the conservation and restoration of a small region of Port of Kaohsiung's original eco-landscapes, the people of Kaohsiung will appreciate the fact that the urbanized and industrialized Kaohsiung once housed the largest mangrove wetland environment in Taiwan (see Figure 11).

\section{Mangrove Restoration and Observation}

To increase the environmental adaptability and survival rate of the mangrove species and associated plants in the Park, trial and exchange growth mechanisms of mangrove seed breeding were conducted. The results from the first test growths were: (1) Rhizophora stylosa (Griff.) was planted on January 22, 2011, partial wilting and deaths occurred on February 10, 2011; and (2) Kandelia obovata was planted on January 22, partial 
wilting and deaths occurred on February 13. The Lumnitzera racemosa and Avicennia marina that were planted at the same time as the above species have survived to this date (see Figures 12-17). Future strategies will be first to adjust the positions of different species, and if deaths continue, the Rhizophora stylosa and Kandelia obovata species from other areas of Taiwan will be exchanged. If wilting persists, then the species will be exchanged to the onsite species that have responded well to restoration, preventing further loss of mangrove seeds.

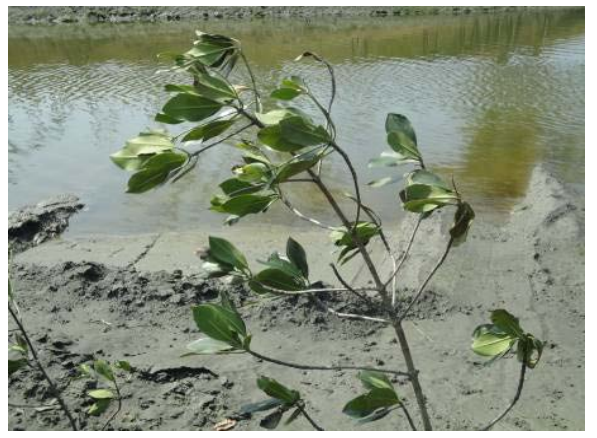

Figure 12. Rhizophora stylosa (Griff.) test growths on January 22, 2011.

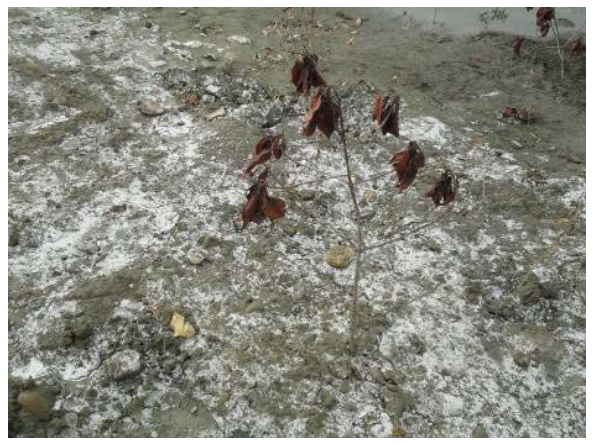

Figure 13. Rhizophora stylosa (Griff.) partial wilt and death on February 10, 2011.

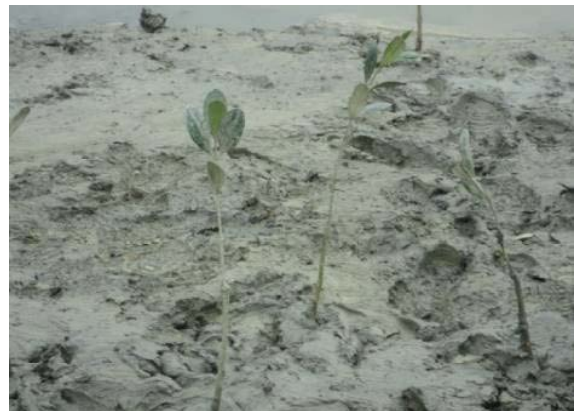

Figure 14. Kandelia obovata (Sheue, Liu, \& Young) test growths on January 22, 2011.

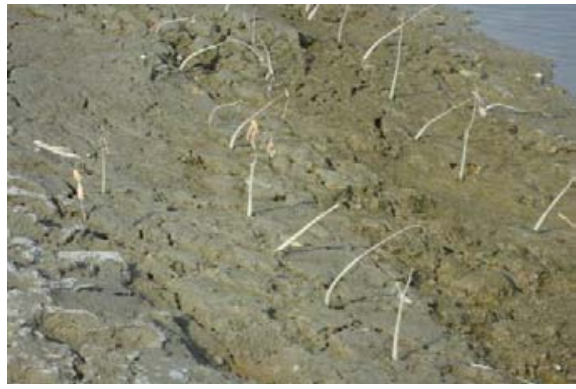

Figure 15. Kandelia obovata (Sheue, Liu, \& Young) partial deaths on February 13, 2011. 


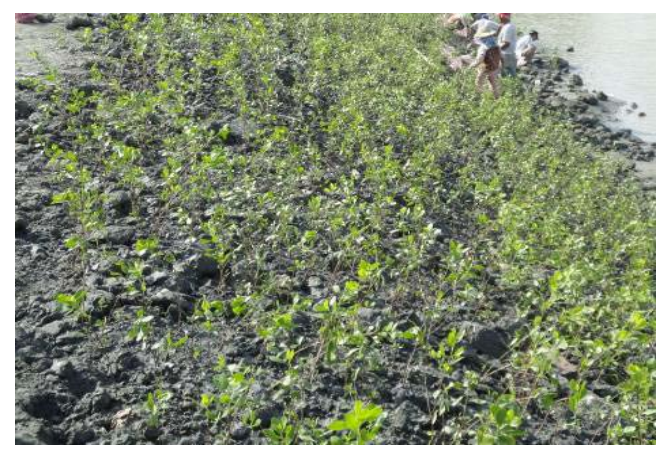

Figure 16. Lumnitzera racemosa (Willd) in good condition, February 22, 2011.

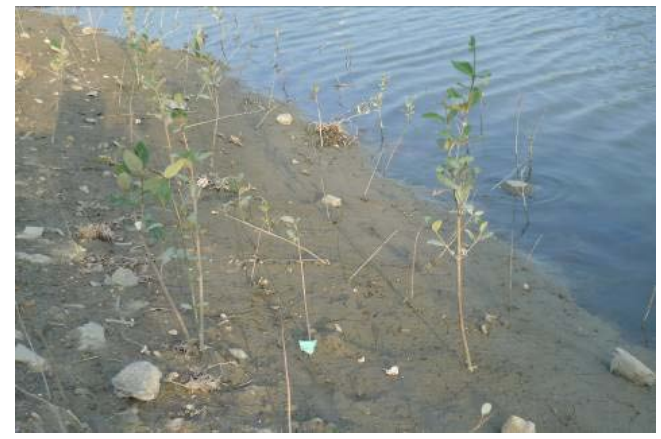

Figure 17. Avicennia marina (Forsk.).Vierh in good condition, February 13, 2011.

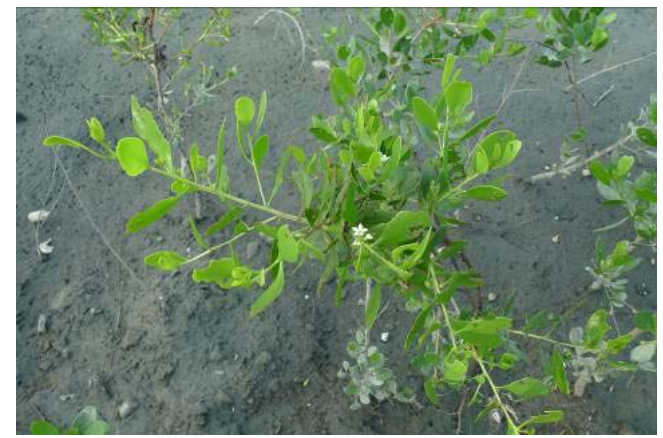

Figure 18. Lumnitzera racemosa (Willd) has a healthy growth of white flowers, January 3, 2012.

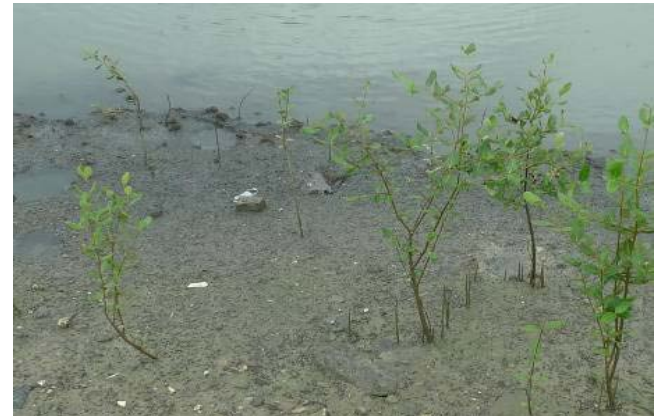

Figure 19. Avicennia marina (Forsk.) Vierh has grown stronga aerial roots, January 3, 2012. Source: photos from the current study.

According to the latest monitoring dated Jan. 3, 2012, one year after the planting, both Lumnitzera racemosa and Avicennia marina are growing in good condition. While the Lumnitzera racemosa is blooming 
healthily with small white flowers (see Figure 18), the Avicennia marina is thriving with strong aerial roots (see Figure 19), and both have developed symbioses with their surrounding biological environment. The monitoring results reveal that they are the most successfully restored species in Jhong-Dou Park (see Figure 20).

It is recommended that the Kaohsiung City government commission academic and civilian organizations to commit manpower to monitor wetland ecology using web cameras on the observation tower, and to continuously monitor mangrove and associated plant restoration. In addition, the biological cycles of bird life, insects and animals (such as mudskippers, fiddler crabs, clams and other primary producers) can also be monitored and recorded, and this data can be submitted for publication and feedback to review and improve the design phase of the project. Aside from the Chinese version, these publications can be translated into an international version for reference by related organizations.

\section{Jhong-Dou Wetland Park Management Plan}

The success of wetland vegetation restoration relies on highly professional execution and continuous concern from the general public. For the first five years of mangrove and associated vegetation restoration in the Jhong-Dou Wetland Park, tourists will be prohibited to approach the restoration grounds. After the vegetation restoration is completed, the following proposals should be consulted as the model policies for future management of the Park:

(1) Persuasion from the park management and installation of explanation and dissuasion plaques;

(2) Set up a list for monitoring, including mangrove forest, water quality, bird life and animal life;

(3) Conduct regular sampling tests of mud bottoms to understand the source of mud detritus and contamination;

(4) Protection plan for the mangrove stocks;

(5) Establish monitoring databases on bird, wild life and plant life;

(6) Conduct academic exchanges with similar wetland monitoring case reports, both domestic and abroad;

(7) Trimming and skimming mangrove plants that have affected landscapes and the safety of tourists; branches will be used for local organic fertilizer;

(8) Provide surplus seeds from successful restoration to areas that needed mangrove restoration and stock protection;

(9) Regular dredging work for river channels, maintain the widths and depths of the channels to sustain flood detention and recreation functions;

(10) Because of its unique structure, floating waste will get caught in the roots of mangrove trees. This waste need to be cleaned regularly by boat crews. A solution to this problem is to tightly control the closing and opening of the water gates;

(11) Establish biological prevention methods for mosquitoes that may become disease vectors;

(12) For the selection of coastal vegetation, endemic species from the Shou-shan Mountain and the surrounding environment should be prioritized;

(13) Set up controlling mechanisms by zones for boat cruise and visitor hours to the park;

(14) Mangrove ecology education service and employment training;

(15) Management of visitor behavior;

(16) Set up an information center;

(17) Management of tidal schedule; to accommodate future boat cruises in the park, a tidal schedule 
should be available on hand to inform tourists of boat cruise operating hours;

(18) Application for the status of Nationally Significant Wetlands.

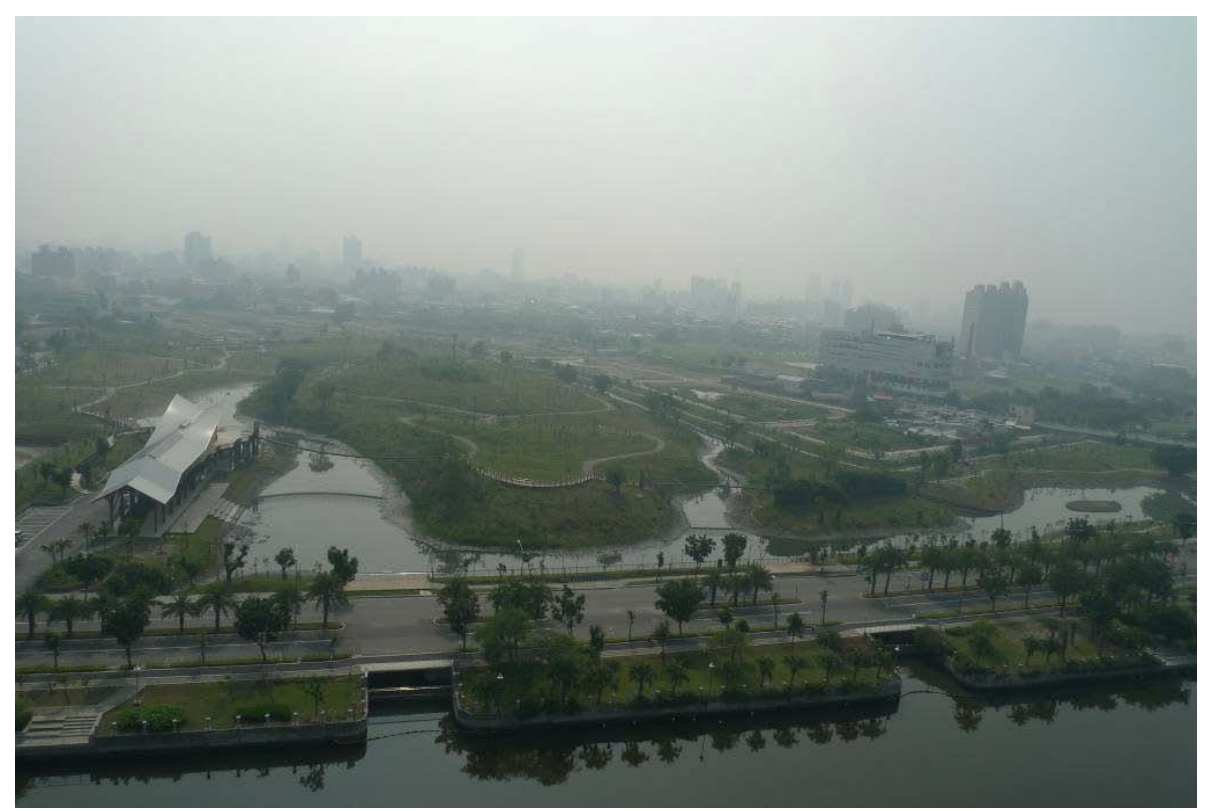

Figure 20. Onsite photo of the Jhong-Dou Wetland Park. Source: Photos from the current study.

\section{Conclusion}

The completion of the Jhong-Dou Wetland Park will carry a multitude of functions that include recreation, environmental education, urban flood detention and finalization of the Wetland eco-corridor connection project. The mangrove restoration effort, particularly, can be viewed as the key experiment in the ecological restoration of Kaohsiung. The data collected from the growth records of vegetation can be used as reference for not just the Park itself, but also made available to other restoration areas in Taiwan or similar wetland restoration projects in other nations. The construction of the Jhong-Dou Wetland Park is an example case of humans trying to undo the damage done to Mother Nature.

\section{References}

Chapman, V. J. (1970). Mangrove phytosociology. Tropical Ecology, 11(1), 1-19.

Hu, C. H. (1959). Study of mangrove in southern Taiwan. Journal of Taiwan Museum, 2, 77-96.

Jin, L. (1982). The world's mangrove. Quarterly Journal of Chinese Forestry, 15(3), 3-8.

Liu, T. R. (1982). Mangroves in Taiwan. Quarterly Journal of Chinese Forestry, 15(3), 9-16.

Polunin, N. (1960). Introduction to plant geography and some related sciences.

Waisel, Y. (1972). Biology of Halophytes. N.Y. Academic.

Xue, M. L. (1995a). Disappearing wetlands forest-Logging of mangroves in Taiwan. Taiwan Endemic Species Research Institute.

Xue, M. L. (1995b). Important mangrove habitat survey in Taiwan. Symposium on Mangrove Ecosystems, 99-106. 